\title{
THE SEPTEMBER ISSUE Some Things Old and Some Things New
}

WE HAVE AN EXCITING LINEUP for you in this September issue of Oceanography, touching many of the bases that make our journal stand out within the ocean sciences community. In addition to traditional science articles, we have a paper on belonging, accessibility, justice, equity, diversity, and inclusion (BE A JEDI); another on capacity-building in the ocean sciences; and a DIY Oceanography contribution. This issue's education section features columns on undergraduate teaching and careers post graduate school, and we present a new Navigating Grad School section. We also have a book review to share, and the third consecutive column from the TOS JEDI Committee.

The lead science article by Meyer-Gutbrod et al. discusses the challenges facing North American right whale populations due to climate-driven changes in the Gulf Stream. Related perspectives are provided by Record and Pershing and Pendleton, and Friel gives readers a whale's eye view of how entanglements in fishing gear are leading to devastating losses of this species. Meyer-Gutbrod et al. urge federal agencies in Canada and the United States to consider adopting more dynamic management plans to save these whales from extinction. On another topic, Villalobos et al. describe how they combined acoustic, optical, and environmental sampling to survey fish populations in a marine protected area in the Gulf of California, an approach they suggest is practical for obtaining baseline information on marine protected areas and for efficiently monitoring changes.

A feature by Urban and Seeyave provides the lessons learned by the Partnership for Observation of the Global Ocean (POGO) and the Scientific Committee on Oceanic Research (SCOR) in conducting visiting scientist programs to assist developing countries as they build self-sustaining ocean science and observational communities. Among the things POGO and SCOR have learned is that training in-country has many benefits, including the ability to reach a larger number of trainees. Inspired by a session at the 2020 Ocean Sciences Meeting, the article by Behl et al. shares various strategies for promoting belonging, accessibility, justice, equity, diversity, and inclusion in the coastal, ocean, and marine sciences, with the hope that our community will be inspired to take action individually or collectively.
Chava et al. contribute a paper to our long-standing Breaking Waves section that demonstrates a simple and cost-effective method for studying biofouling in deep waters $(>50 \mathrm{~m})$. They show how a variety of autonomous seafloor equipment can be used as supporting platforms for biofouling studies. As a reminder to our readers, the purpose of Breaking Waves is to present short papers that describe novel approaches to multidisciplinary problems in oceanography. We welcome contributions to this section, and author guidelines are available on the Oceanography website (https://tos.org/oceanography/guidelines).

We are very pleased to publish our fourth DIY Oceanography article in two years. With guest editors Melissa Omand and Emmanuel Boss, we introduced DIY Oceanography just over a year ago. In this issue, Pagniello et al. describe their customdesigned optical imaging system that captures images in situ in ambient light, show how they used this home-built system, and provide instructions on how to build the system yourself. We have started a new page on the TOS website to help readers find all of the published DIY Oceanography papers. You can find it at https://tos.org/diy-oceanography.

As a final note regarding this September issue, I urge graduate students and instructors alike to read the first contribution to the new Oceanography section called Navigating Grad School. In the inaugural article, Franks shares his wisdom on how to envision and write a thesis proposal, knowledge he has gained while mentoring and advising hundreds of graduate students at Scripps Institution of Oceanography. I look forward to receiving suggestions from our readers for topics we might cover in this new section. At the same time, instructors are also encouraged to read The Oceanography Classroom, where guest columnist Freeman shares how she engages her introductory oceanography class to learn new terms and concepts in marine ecology. And in the Career Profiles section, we share two new profiles.

We welcome comments about and suggestions for Oceanography, and as we listen to the diverse voices in our community, we will continue to respond to them by experimenting with new sections and columns as we have in this issue.

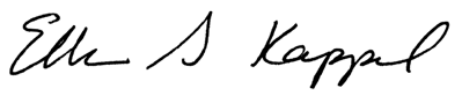

Ellen S. Kappel, Editor 